\title{
Cultural History and Modern Science
}

\author{
Max Long
}

Faculty of History, University of Cambridge, Cambridge, UK Email: mel58@cam.ac.uk

Being modern: the cultural impact of science in the early twentieth century. Edited by Robert Bud, Paul Greenhalgh, Frank James, and Morag Shiach. London: UCL Press, 2018. Pp. 438. ISBN 9781787353930. £0.00 (open access PDF); £50.00 hbk.

The wild within: histories of a landmark British zoo. By Andrew Flack. Charlottesville: University of Virginia Press, 2018. Pp. 272. ISBN 9780813940953. \$39.50 hbk.

Animal subjects: literature, zoology and British modernism. By Caroline Hovanec. Cambridge: Cambridge University Press, 2018. Pp. 232. ISBN 9781108428392. $£ 75.00 \mathrm{hbk}$.

Coral empire: underwater oceans, colonial tropics, visual modernity. By Ann Elias. Durham: Duke University Press, 2019. Pp. x+286. ISBN 9781478003823. \$99.95 hbk; $\$ 26.95$ pbk.

News from Mars: mass media and the forging of a new astronomy, 1860-1910. By Joshua Nall. Pittsburgh: University of Pittsburgh Press, 2019. Pp. 312. ISBN 9780822945529. \$50.00 hbk.

The term 'cultural history of science', as others have observed, is clumsy and imperfect. Cultural history is itself riddled with ambiguities which the addition of 'science' is unlikely to clarify. ${ }^{1}$ However, the term loosely describes a genre of historical writing which has become a staple of cross-disciplinary research: books which examine science's wider cultural 'impacts' and 'contexts'. The

\footnotetext{
${ }^{1}$ For earlier assessments of science and cultural history, see Peter Dear, 'Cultural history of science: an overview with reflections', Science, Technology, \& Human Values, 20 (1995), pp. 150-70; Joseph Rouse, 'What are cultural studies of scientific knowledge?', Configurations, 1 (1993), pp. 1-22. See also James Poskett, 'Science in history', Historical Journal, 63 (2020), pp. 209-42.

(C) The Author(s), 2021. Published by Cambridge University Press. This is an Open Access article, distributed under the terms of the Creative Commons Attribution licence (http://creativecommons.org/licenses/by/4.0), which permits unrestricted re- use, distribution and reproduction, provided the original article is properly cited.
} 
heterogeneity of this field is so great, however, that an examination of methodology is called for.

Some of the finest cultural histories have emerged from studying the history of science. In 2004, Peter Mandler argued that historians of science 'had their epistemological crisis before most of the rest of us': because their sources were so often concerned with claims to authenticity and scientific objectivity, they were primed to account for what he called "the relative "throw" - the weight of significance' of historical evidence. ${ }^{2}$ Historians of science adopted social and cultural methods beginning with the 'cultural turn' of the 1980s, culminating in a series of seminal books in the early 2000s. Jim Secord and Bernard Lightman, for instance, focused on Victorian Britain, drawing from material culture and challenging earlier hierarchical and top-down models of knowledge diffusion by richly documenting the fluid boundaries between formerly accepted categories like 'professional' and 'amateur'. ${ }^{4}$ These scholars incorporated popular culture not only as reflective, but as co-constitutive of scientific thought, using terms like 'circulation' and 'formation'. ${ }^{5}$ This research was influenced partly by cultural history and partly by sociology, latterly in the work of Bruno Latour and Sheila Jassanoff, who emphasized terms like 'construction' and 'co-production'. ${ }^{6}$ The 'impact', then, of science was not about one-way traffic, nor was it measured by isolated case-studies purporting to show science pouring out from closely guarded test-tubes. What previously was interpreted as 'dissemination' or 'popularization' is today recognized as more than mere 'impact': it is part and parcel of scientific culture.

But cultural histories of science are not solely the preserve of science historians. Adjacent disciplines began to explore aspects of scientific history around the same time as historians of science were turning to cultural and social history. In literary studies, Gillian Beer, Michael Whitworth, and Daniel Albright addressed the impact on modernist writing of, respectively, Darwinism, relativity, and quantum theory. ${ }^{7}$ These scholars established the fascination with turn-of-the-century science and technology as a central

\footnotetext{
${ }^{2}$ Peter Mandler, 'The problem with cultural history', Cultural and Social History, 1 (2004), pp. 94117. For a recent reconsideration of Mandler's thesis, see Christine Grandy, 'Cultural history's absent audience', Cultural and Social History, 16 (2019), pp. 1-21.

${ }^{3}$ On the adoption of social and cultural historical methods by historians of science, see Dear, 'Cultural history of science'; and Poskett, 'Science in history', pp. 230-6. See also Robert E. Kohler and Kathryn M. Olesko, 'Introduction: Clio meets science', Osiris, 27 (2012), pp. 1-16.

${ }^{4}$ James Secord, Victorian sensation: the extraordinary publication, reception, and secret authorship of vestiges of the natural history of creation (Chicago, IL, 2000); Bernard Lightman, Victorian popularizers of science: designing nature for new audiences (Chicago, IL, 2007). See also Steven Shapin, 'Science and the public', in R. C. Olby et al., eds., Companion to the history of modern science (London, 1990), pp. 990-1007.

${ }^{5}$ James Secord, 'Knowledge in transit', Isis, 95 (2004), pp. 654-72; Roger Cooter and Stephen Pumfrey, 'Separate spheres and public places: reflections on the history of science popularization and science in popular culture', History of Science, 32 (1994), pp. 237-67.

${ }^{6}$ See Lorraine Daston, 'Science studies and the history of science', Critical Inquiry, 35 (2009), pp. 798-813.

${ }^{7}$ Gillian Beer, Darwin's plots: evolutionary narrative in Darwin, George Eliot and nineteenth-century fiction (Cambridge, 1983); Michael Whitworth, Einstein's wake: relativity, metaphor, and modernist
} 
dimension of modernism. They were also often interested in the production and circulation of knowledge among different audiences, documenting, for instance, what Beer called 'the transformations that occur when ideas change creative context and encounter fresh readers'. ${ }^{8}$ Scientific images, too, were scrutinized by scholars of visual culture, including James Elkins, Jennifer Tucker, and Horst Bredekamp. ${ }^{9}$ Moreover, the incorporation of science as one of many components of 'culture', and the growing interest in the history of knowledge and its circulation in global and imperial history, has increasingly seen historians of science being hired by traditional history departments, further blurring disciplinary lines. ${ }^{10}$ The five books reviewed here - one edited collection and four monographs by a literary scholar, an art historian, an historian of science, and an animal historian - offer a glimpse into current developments in the 'cultural history of science' field, if we may call it that. The monographs are each interdisciplinary, and yet they represent distinct methodological approaches. All five books focus largely on the anglophone world and identify the first half of the twentieth century as a key period during which science transformed culture and contributed to making it 'modern'. As a whole, they share a notion of modernity and of science which is intrinsically tied to Western forms of knowledge production and consumption. Although this review concentrates on this period and context, it is hoped that the questions it raises, especially those relating to the history of animals, the use of images as historical evidence, or the role of media in the history of knowledge, will be pertinent to scholars of other times and places.

The seventeen essays in Being modern: the cultural impact of science in the early twentieth century revolve around a central question: how do we fit scientific knowledge into our explanations of modernity? The turn of the century is often regarded as the birth of 'modern' science and culture, but studies of this phenomenon have mostly focused on the nineteenth century. ${ }^{11}$ Being modern is a necessary intervention which addresses this imbalance while challenging disciplinary boundaries, uniting a 'confluence of scholars from disciplines that do not always talk to each other in depth or productively' (p. 7). The

literature (Oxford, 2001); Daniel Albright, Quantum poetics: Yeats, Pound, Eliot, and the science of modernism (Cambridge, 1997).

${ }^{8}$ Gillian Beer, 'Translation or transformation? The relations of literature and science', Notes and Records of the Royal Society of London, 44 (1990), pp. 81-99, at p. 81.

${ }^{9}$ James Elkins, 'Art history and images that are not art', Art Bulletin, 77 (1995), pp. 553-71; Jennifer Tucker, Nature exposed: photography as eyewitness in Victorian science (Baltimore, MD, 2005); Horst Bredekamp, Vera Dünkel, and Birgit Schneider, eds., The technical image: a history of styles in scientific imagery (Chicago, IL, 2015). See also Geoffrey Belknap, From a photograph: science and the periodical press, 1870-1890 (London, 2016), pp. 1-14.

${ }^{10}$ Poskett, 'Science in history', p. 236; Peter Burke, What is the history of knowledge? (Cambridge, 2016); Sarah Easterby-Smith, 'Recalcitrant seeds: material culture and the global history of science', Past \& Present, 242 (2019), pp. 215-42.

${ }^{11}$ Lorraine Daston calls the period around 1900 science's third 'modernity'. See Lorraine Daston, 'When science went modern', Hedgehog Review, https://hedgehogreview.com/issues/the-culturalcontradictions-of-modern-science/articles/when-science-went-modern, accessed 3 Sept. 2020. On writing the history of twentieth-century science, see Joseph D. Martin, 'Who owns the twentieth century? (And is it worth owning?)', Isis, 108 (2017), pp. 149-57. 
inclusion of essays on a wide range of scientific disciplines, structured over four sections, also reminds us of the futility of interpreting 'science' as a totalizing category. Being modern broadens scholarship on the cultural history of science in several ways. By moving the emphasis from 'modernism' towards 'being modern', popular scientific culture shifts into focus, as do more vernacular engagements with scientific ideas. Here, Charlotte Sleigh's chapter on science fiction magazines stands out. Moving beyond literary modernism also means that sculpture and architecture are incorporated, although one wonders whether two separate chapters on Le Corbusier were called for. Furthermore, the overlap between technology and science is examined in depth, and mass media has a prominent place in several essays, including Tim Boon's on industrial film. Robert Bud's chapter on applied science is especially strong, using the term's ambiguity as an opportunity to delve into how the public experienced science 'through the names of departments and degrees in modern subjects, in engagement with exhibitions, in popular books and lectures, in films and on the radio' (p. 121). Finally, radio is explored in two fine chapters by Michael Guida and Jeff Hughes.

Hughes, whose contribution examines the links between amateur wireless knowledge and its military and industrial uses in nuclear physics, sums up the trouble with many cultural histories of science:

Much analysis of cultural modernism and the sciences...tends to essentialise this 'modern physics' and to see it as a given - a grounded, selfevident domain which indeed could be appropriated, reflected and refracted by other contemporary cultural forms as they sought to create, sustain or modify their own senses of modernity. (p. 249)

Too often, therefore, science is treated as a fixed entity whose 'impacts' on wider society can be studied by cultural historians. Not all the essays in Being modern succeed in moving away from this assumption, but as a survey of the wide range of approaches and methodologies available to cultural historians of science it is a valuable and welcome resource.

Literary sources arguably present some of the biggest difficulties in writing cultural histories of science, accustomed as we are to using literature as a barometer for social, political, and scientific 'impact'. The environmental turn in literary studies has begun to generate a rich scholarship exploring the history of the life sciences as it relates to literature. ${ }^{12}$ A recent example of this is Caroline Hovanec's Animal subjects: literature, zoology and British modernism, which argues that an obsession with 'animal subjectivity' produced 'a shared domain, an area of inquiry inherently unbounded by discipline' for literary modernists and early twentieth-century zoologists. In four chapters, Hovanec explores how H. G. Wells, Charles Elton, Aldous Huxley, Henry Eliot

\footnotetext{
${ }^{12}$ See, for instance, Christina Alt, Virginia Woolf and the study of nature (Cambridge, 2010); Jeffrey Mathes McCarthy, Green modernism: nature and the English novel, 1900 to 1930 (New York, NY, 2015).
} 
Howard, D. H. Lawrence, Conwy Lloyd Morgan, Julian Huxley, and Virginia Woolf all shared a deep curiosity for the inner worlds of animals.

These examples, Hovanec argues convincingly, "blurred the boundaries between literary and scientific forms of description, and...ways of knowing' (p. 5). Hovanec resists a top-down or unidirectional interpretation of science's impact on culture, and she embraces the often-contradictory slippages between science and literature. 'Scientific writing about animals creates aesthetic experiences', she argues, just as 'literary writing about animals produces knowledge' (p. 31). Evidencing intellectual and social connections between scientists and artists is a murky business at best, and in recognizing this, Hovanec takes her cue from Gillian Beer, seeking 'loose accords' that link her network of characters (p. 16). The definition of the term 'animal subjectivity' might be too vague for some readers' tastes (pp. 17-18). But in many respects, it is a highly productive term: had Hovanec adopted a narrower focus on 'ethology' or 'zoology', the book would have excluded some of the more ambiguous explorations of animal subjectivity which she identifies across literary and scientific writing. One takeaway of this approach is that it suggests a reappraisal of certain modes of description, like anthropomorphism, which in Hovanec's view has too often been dismissed as 'unscientific and sentimental' (p. 29). Zoological descriptions by scientists and modernist writers offer a positive reading of anthropomorphism as 'at once intellectually intolerable and artistically fruitful' (p. 201), bridging the conceptual gap between non-human and human worlds.

Animal subjects is a thorough and enjoyable book, packed with insights about the overlapping interests of scientists and writers. It is a historicist study which offers solid evidence of how modernist writers and zoologists shared stylistic and formal techniques in their attempts to understand animal lives. These modes of writing emerged as a response to a problem - the ultimate inaccessibility of animal experience from a human point of view. This approach yields insightful observations into the shifting languages and styles of animal writing in the early twentieth century. Hovanec's detailed assessment, in the first chapter, of H. G. Wells's stylistic shift from a Darwinian 'bio-pessimism' to a techno-utopian philosophy is successfully mapped through the development of applied ecology. Equally strong is her analysis of 'thin' and 'thick' description in subsequent chapters. The former, used by Aldous Huxley and Nikolaas Tinbergen, was an objective mode of observation that departed from Victorian anthropomorphism. 'Thick description', on the other hand, favoured by D. H. Lawrence and Julian Huxley, treated animals as 'feeling, expressive subjects not unlike human beings' (p. 158). The final chapter, which links comparative psychology and the Bloomsbury group with the rise of an empirical mode of describing animal subjectivity, argues that this period witnessed the inception of an understanding of animal life which persists today.

Hovanec's approach is rooted in a subset of literary studies that has done much to advance our historical understanding of the culture of science. Occasionally, however, there is a risk of using literary criticism as a kind of scientific gatekeeping, of admitting the modernist canon into the laboratory, so to speak. Hovanec sometimes veers into this territory, such as when she justifies her choice of subjects on the grounds that they were 'scientifically 
literate' (p. 119). In her excellent essay on science fiction magazines in Being modern, Charlotte Sleigh observes that:

Usually historians and literary critics treat something as worthy of their attention if it is either a mass phenomenon, or if it is connected to a person or institution that is already regarded as important. The latter is selfconfirming, resulting in ever deeper scholarly grooves being cut, in the modern period, for such figures as Woolf or Haldane. (p. 151)

Tellingly, Hovanec dedicates ample space to both Woolf and Haldane in the last chapter. The inevitable question arises, therefore, of whether 'modernism' is really the best term to describe Hovanec's subject matter. After all, a fascination with animals' inner lives ran very deep during this period: Hovanec's modernists shared their curiosity not only with leading scientists, but also with a considerable proportion of the British public, who bought natural history books, listened to wildlife broadcasts, and visited zoos in their millions. ${ }^{13}$ Hovanec does not ignore this wider appeal - in the introduction, she refers to an 'explosion of scientific and popular zoology' (p. 4) - but it is not a principal concern of the book. Connecting the dots between literary, scientific, and popular engagements with animal subjectivities, therefore, suggests itself as one avenue for further investigating the questions raised by Hovanec in this engaging cultural history of modern(ist) science. ${ }^{14}$

Andrew Flack's The wild within: histories of a landmark British zoo springs from a similar interest in animal studies and environmental history. ${ }^{15}$ An ambitious work centred around one institution, Bristol Zoo, Flack's book reveals multiple levels of dissection and engages with some of the major questions in environmental history. Eschewing a chronological approach, Flack covers the zoo's history from its foundation in 1835 to the present day in six thematic chapters which consider larger issues like the commodification of animals, the changing experience of the zoo visit, the medicalization of animal bodies, and the shifting representations of animals' inner lives. This permits an expansive take on the history of human-animal relationships which stretches far beyond the history of Bristol Zoo, and allows the conceptual and methodological problems of writing animal histories to come to the fore. In the book's conclusion, Flack justifies his thematic approach in part because of larger continuities that were revealed in the course of his research:

\footnotetext{
${ }^{13}$ See Peter Bowler, Science for all: the popularization of science in early twentieth-century Britain (Chicago, IL, 2009).

${ }^{14}$ Hovanec herself has already begun to do this, with an excellent article on the interwar short film series Secrets of nature. See Caroline Hovanec, 'Another nature speaks to the camera: natural history and film theory', Modernism/Modernity, 26 (2019), https://modernismmodernity.org/articles/another-nature-speaks.

${ }^{15}$ Lorraine Daston and Gregg Mitman, eds., Thinking with animals: new perspectives on anthropomorphism (New York, NY, 2005); Susan Nance, ed., The historical animal (Syracuse, NY, 2015); Hilda Kean and Philip Howell, eds., The Routledge handbook of animal-human history (London, 2018).
} 
In some ways, animals were treated in the same way at the beginning of the twenty-first century as they were at the beginning of the nineteenth. Despite changes over time, they were consistently objectified within economic systems, either in the wild animal trade itself or through their deployment in the generation of revenue and in systems of knowledge acquisition. (p. 183)

The book's thematic organization permits these continuities to be observed more clearly, but it also allows Flack to account for significant changes, from the physical infrastructure of the zoo to the way humans engaged with, studied, and thought of captive animals.

Flack identifies three main periods in the history of Bristol Zoo, which also map onto the history of zoos in general: its origin and popularity in the nineteenth century, followed by a period of consolidation and eventual decline in the twentieth, and subsequently a renewed, conservation-oriented interest beginning in the 1980s. However, he repeatedly turns to the first half of the twentieth century to explain how the display of zoo animals, and human understandings of animal life more broadly, changed dramatically. The replacement of metal cages with glass panels, pressure from animal welfare campaigners resulting in legislative protection for captive animals, the impact of changing technologies and mass media, and the growing characterization of zoo animals as domesticated - Flack calls them 'zoo pets' - all contributed to the formation of the modern zoo, and significantly shaped public understandings of animal life. Science appears most prominently in Chapter 3, where he discusses how zoo animals were subjected to an intense medical and zoological gaze' (p. 93). This analysis touches on the professionalization of zoo veterinary as well as the significance of Charles Darwin, and later animal behaviour and ethology, in justifying the use of animals as a live spectacle, providing a simultaneous experience of education and entertainment. This chapter encapsulates something which is implied throughout the book: the rise in the zoo's popularity, and the increasing tendency to anthropomorphize animals and their lives, did not develop at the expense of zoological knowledge. Instead, the twentieth century witnessed a rise in both phenomena, such that seeing them as separate developments becomes untenable. That Flack does not always approach this question using science as his starting point does not detract from the book's value as a cultural history of science; instead, it facilitates a more nuanced approach to the ways in which science was experienced by the public. It also allows Flack to blend in other elements of popular science with which zoos overlapped, including film, television, newspapers, and children's stories. The fourth chapter, which concerns human-animal relationships at the zoo, is especially rich in utilizing this kind of evidence, and ultimately hinges on the recognition that, while awareness of animals' 'rich inner lives' grew during the twentieth century, 'the reality is that these lives were fundamentally challenging to access' (p. 125).

And, we might add, they remain equally challenging to access for the historian. Flack's book poses difficult questions for writing cultural histories of science which fully incorporate animal life and agency, although he prefers 
the term 'influence'. Animal histories, and the wider field of animal studies, have already gone a long way in establishing the importance of animal lives in specific historical contexts. But this work is often at odds with traditional histories of science, which sometimes treat animal subjects with the same objective eye as historical scientists. Animal histories have therefore filled in the 'cultural gap' left by historians of science, and Flack's book contributes to this field by arguing that the zoo was a key site for the production of knowledge about captive animals. The final chapter of the book, for instance, tries to move away from an account of the zoo's 'impact', instead proposing that it represents 'not only a space in which human fantasies about animals and the rest of the world manifest, but also...a hybrid space, an ecosystem in its own right' (p. 155). A critical component of this ecosystem concerns how animal behaviours and reactions, as expressed within their conditions of captivity, affected their representations. Animals escaping, turning violent, or engaging in other forms of transgression continually led to changes in the zoo's practices and even its architecture. Flack is careful not to overstate this influence zoo animals emerge in his book not as masters of their own destiny, but as active co-producers in a complex mesh of actors. Flack's treatment of animal influence, therefore, returns us to some of the issues surrounding 'impact' with which this review began. How much influence should we attribute to individual animals, or individual species, in shaping cultural understandings of animal lives? Is the behaviour of animals as historically significant as the forms of knowledge-gathering and representation that shaped our understandings of them? And how fully should we incorporate animals into our definition of 'culture'? The wild within does not always give clear answers to these questions - that would be too much to ask of a relatively slim volume - but it does suggest that cultural histories of science are well equipped to explore them further.

Given the entanglement of scientific knowledge production with economic and cultural power in the British empire, cultural histories need to pay close attention to how imperial ideologies and institutions shaped twentiethcentury science. ${ }^{16}$ Although The wild within explores the zoo as a site for the performance of imperial dominance, it offers relatively few historiographical pointers on this question. The association between the British imperial project, scientific racism, and early twentieth-century zoology might also have merited a more detailed consideration in Hovanec's Animal subjects. Ann Elias's Coral empire, on the other hand, locates empire at the heart of a primarily visual history of twentieth-century underwater science. Empire is not its only focus, however, for it also responds to a 'shift in focus from land to sea' in the environmental humanities (p. 6). Coral empire is a book about the emergence of coral reefs as a 'modern spectacle' (p. 209), and Elias treats photographic and film technology as pivotal agents in this transformation. The book is grounded in

\footnotetext{
${ }^{16}$ See Axel Jansen, John Krige, and Jessica Wang, 'Empires of knowledge: introduction', History and Technology, 35 (2019), pp. 195-202; Peder Anker, Imperial ecology: environmental order in the British empire, 1895-1945 (Cambridge, MA, 2002); Richard Drayton, Nature's government: science, imperial Britain and the 'improvement' of the world (New Haven, CT, 2000).
} 
the parallel stories of two photographers - J. E. Williamson and Frank Hurley and two locations - the coral waters of the Bahamas and the Great Barrier Reef in Australia. This focus allows Elias to engage in a close and detailed analysis of place and personality while unravelling a broader story that accounts for the role of technology in shifting the representation of the underwater in the public imaginary. The book also deals with the correspondence between exploration and the visual representation of coral reefs, the environmental degradation that this entailed, and the colonial context which saw indigenous bodies depicted alongside - or in other cases erased from - natural habitats.

The book departs from a single photograph taken in 1929 by J. E. Williamson, a pioneer of underwater photography, depicting corals off the coast of the Bahamas. This image was sold by Williamson to a photo agency which in turn circulated it widely. It was later purchased by the surrealist André Breton, who renamed it 'The Australian Great Barrier' when he published it as an illustration in L'amour fou (1937). Following the trajectory of this and several other images produced by Williamson in the Bahamas and by Hurley in Australia, Elias performs an impressive analysis of how scientific images of the undersea were produced, circulated, and later resurfaced. Elias satisfactorily lays out how public perceptions of the underwater changed, as the focus shifted from looking down at corals from above ground, to submerging the viewer (and sometimes the camera itself) to beneath sea level. Coral empire uses careful cross-referencing, and although the book is principally about films and photographs, Elias demonstrates how closely these were interwoven into a wider visual culture that included dioramas, aquariums, and widely circulated newspapers and magazines:

Through mass media in the early twentieth century, the 'coral empire' that was shaped by social and physical interactions between colonialists and coral colonies turned into an empire of coral images that were released in the world through the expanding media world of magazines, newspapers, advertisements, cinema, and postcards. (p. 24)

The careful incorporation of these materials is not only impressive for its scope: it also makes a watertight argument for the cultural significance of modern underwater image-making. Elias's story is, at its core, about how the seabed was made 'modern'. From the technologies that they used, to their desire to engage in macho exploration and the ways that their images were circulated, Elias's subjects were intent on casting themselves in a modern light. The book leaves no doubt that Hurley and Williamson's work precipitated these developments, and Elias goes to great lengths to describe the technical feats achieved by both men, as well as highlighting their collaborations with museums, academic scientists and other institutions.

However, while Coral empire meticulously tracks the production, reception, and circulation of underwater images, Elias does not always treat them as scientific. For instance, of Williamson, she says that he thoped he would be seen as writing a new page in science, but his style of writing signaled showmanship and was more typical of popular, mass media entertainment than the 
comparatively reserved language of scientists' (p. 99). A different analysis of these images might argue that, far from showcasing firm distinctions between science and entertainment, they demonstrate the continual interweaving of both genres. At other times, Elias makes more of this interweaving, such as when she explains how the underwater photography Hurley and Williamson pioneered, already synonymous in the public mind with the study of sea life, soon became indispensable to the scientific study of coral reefs. Chapter 9, for instance, describes the collaboration between Hurley and the Australian Museum ichthyologist Allan McCulloch in making the film Pearls and savages (1923). 'McCulloch the scientist, like Hurley the artist', Elias explains, 'observed no strict differences between science and art, or between pedagogy and entertainment' (p. 162).

Further methodological questions of interest to cultural historians arise from reading Coral empire. One is the tendency in scholarship about scientific images to focus on the well-trodden question of authenticity, or 'nature faking.' ${ }^{17}$ Elias's book documents some intriguing examples, such as the use of aquariums to replicate 'wild' environments. But the decision, in the final synthesizing chapters, to foreground debates about authenticity overshadows other equally interesting questions raised elsewhere in the book, such as the colonial labour involved in making underwater images, or their environmental impact. This is partly a structural problem, but it is also a methodological one. The book's thirteen short chapters reflect the work's broad intellectual scope, but they also leave the reader wanting a clearer, cohesive historical narrative to bind it together. Notwithstanding, Elias's book is exemplary of the global environmental histories which have risen to prominence in recent years. ${ }^{18}$ Aside from addressing current issues relating to the state of the climate, these books can also show us how Western science's 'modernity' was constructed. Global histories of science, moreover, can help to foreground locations, as in this case the Bahamas, which might otherwise receive scant attention in histories of modern science. ${ }^{19}$ Overall, Coral empire is an achievement of careful scholarship that firmly establishes the indispensability of visual evidence, multi-media research, and imperial contexts in this genre of historical work.

Joshua Nall's News from Mars: mass media and the forging of a new astronomy, 1860-1910 also treats mass media as a harbinger of 'modern' science. This book is a solid account of the widespread fascination with the red planet and its potential harbouring of alien life in the late nineteenth century, although many of its conclusions are pertinent to twentieth-century cultural histories. In four chapters, Nall analyses how knowledge about Mars was contested and disputed by British and American scientists in the period 18601910. His account begins with Richard Anthony Proctor, one of the foremost

\footnotetext{
${ }^{17}$ See, for instance, Derek Bousé, Wildlife films (Philadelphia, PA, 2000).

${ }^{18}$ Two recent examples, exploring the history of climate, are Deborah R. Coen, Climate in motion: science, empire and the problem of scale (Chicago, IL, 2018); and Anya Zilberstein, A temperate climate: making climate change in early America (Oxford, 2016).

${ }^{19}$ On global histories of science, see James Delbourgo, 'The knowing world: a new global history of science', History of Science, 57 (2019), pp. 373-99.
} 
British physicists of the period who was also a keen popularizer. Proctor believed in a radical democratization of scientific knowledge that included publishing mass-market books and writing columns for widely circulated periodicals. Nall argues that this context led to Proctor's formulation of 'imaginative astronomy', an idiosyncratic scientific practice which mixed observation with speculation. Proctor's adoption of a 'new journalism' style of writing, Nall argues, made imaginative astronomy 'the era's most successful scientific commodity' (p. 65).

Although Proctor's influence declined as astronomy moved away from theoretical and philosophical approaches and began to focus more on big-budget telescopes, mass media technologies remained intimately connected to the practice of astronomy, with journalism consolidating its 'vital intermediary role as both receiver and transmitter of information' (p. 99). As Nall explains in the second chapter, geography played a key part in situating media technology at the heart of scientific practice; with the advent of large observatories built in the vast expanses of the American West, the telegraph offered a practical solution for keeping scientists in touch with both their home institutions and the wider public. It also served as an imaginative influence for astronomers who began to hypothesize about the possibility of receiving radio signals from Mars. In the last two chapters of the book, Nall offers two further case-studies that show the centrality of mass media in shaping scientific attitudes about Mars. The third chapter explores the emergence of 'event astronomy', by examining how the Harvard astronomer William Pickering utilized the cable network and print capacities of the Daily Herald during the 1892 Mars Opposition from his observatory in Peru, thus setting the narrative for the discussion of life on Mars for years to come. The fourth and final chapter explores Simon Newcomb's fraught attempt to write the 'Mars' entry for the 11th edition of the Encyclopaedia Britannica, and the rifts within the field of astronomy that it revealed. The dispute over the content of the entry shows that scientists increasingly viewed encyclopaedias as a more permanent medium than newspapers for reaching a wide audience. Nall details the complex web of actors involved in writing the final entry, including publishers, reviewers, and editors, revealing how the publishing process laid bare some of the key conflicts in the Martian debate.

Nall argues that modern astronomy and the mass media were inextricable: they 'grew up together' (p. 4). This is his key contribution, what he calls an 'analysis of media in science rather than science in media' (p. 180). As he explains in Chapter 3:

More than mere conduits, communication technologies are embedded within the working worlds of the sciences - multiplying, stabilizing, and therefore co-constituting the knowledge these worlds produce. This means that as well as thinking of knowledge in transit as a matter of authors and audiences, we also need to think of it as a practical entanglement of scientific praxis and material transmission technologies. (p. 107)

Here, Nall engages with two key recent terms coined by science historians Jon Agar's 'working worlds' and Jim Secord's 'knowledge in transit' - to 
argue that we need to pay attention not only to the ways in which science was 'projected' out into the world through mass media technologies, but also to how the latter were enmeshed into science's everyday. ${ }^{20}$

Nall is, above all, an excellent writer: his definitions are precise, and his interventions in the wider historiography are clear and considered. He is especially interested in 'genre and its relations to practice' (p. 16). Accounting for planetary science's appearance in mass media is not enough: we should also seek to understand how the forms and styles that defined these media became embedded in scientific work. In Nall's view, the history of science is inherently cultural because of how scientific knowledge was published, discussed, and validated in the 'cultural marketplace' (p. 4), which saw practitioners adapting their forms and styles of presenting knowledge to the perceived preferences of consumers. Recognizing the role of different modes of transmission in shaping scientific knowledge is one thing: following through with a thoroughly evidenced account of how this process functioned in practice, as Nall does, is another entirely.

News from Mars works well as a cultural history because it aims to contribute first and foremost not to the history of science in culture, but to the history of astronomy: it departs from an epistemological question about scientific knowledge, and in the process reveals the different ways in which this knowledge was marketed as a cultural product. Conversely, histories which seek to demonstrate scientific 'impact', instead of more dynamic processes of exchange, circulation, and translation, can become unnecessarily constrained by trying to evidence something which is, at best, hard to locate. Taking stock of the entanglement of science in society necessitates a historical methodology which digs a little deeper, seeking evidence not only of the inscription of science in cultural products, but also of how these cultural products themselves influence the production of scientific knowledge. Across the books reviewed here, mass media technology emerges as a loosely unifying theme. Incorporating methods from media history into the study of twentieth-century science - including accounting for 'intermediality' and the material nature of different media including print, radio, sound, and moving images - can complement and enhance the kind of non-hierarchical histories of science with which this review began. ${ }^{21}$ As a metaphor, mediation is also a productive way of thinking about science and cultural history, capturing how knowledge is continually transmitted and transformed in ways that are constitutive of its meaning.

Nevertheless, the four monographs reviewed here portray a field that is characterized above all by its methodological diversity. Each has something unique to offer to those engaged in writing cultural histories of science

\footnotetext{
${ }^{20}$ Jon Agar, Science in the 20th century and beyond (Cambridge, 2013); Secord, 'Knowledge in transit'.

${ }^{21}$ Sian Nicholas, 'Media history or media histories? Re-addressing the history of the mass media in inter-war Britain', Media History, 18 (2012), pp. 379-94. For a recent exploration of media as a methodology in the history of science, see Jeremy A. Greene, 'Knowledge in medias res: toward a media history of science, medicine, and technology', History and Theory, 59 (2020), pp. 48-66.
} 
today. Hovanec proves that literary analysis can connect dots that might otherwise remain elusive or overlooked; Flack elegantly fuses institutional history with an account of animal influence; Elias shows that in-depth research into visual evidence can serve as a springboard to write rich histories connecting science, empire, and the environment; Nall demonstrates that with the right kinds of evidence it is possible to craft satisfying historical accounts of how science functioned in the age of mass media. These literatures are not always in conversation with each other, and they do not form a cohesive historiography. However, they are representative of a diverse set of epistemological approaches to what the editors of Being modern call a 'common interest' (p. 7), which I have referred to here as the 'cultural history of science'.

Acknowledgements. The author would like to thank Peter Mandler, Andrew Arsan, and the two anonymous reviewers for their helpful suggestions and improvements to this review article.

Cite this article: Long M (2022). Cultural History and Modern Science. The Historical Journal 65, 856-868. https://doi.org/10.1017/S0018246X2100042X 